\title{
The skull evolution of oviraptorosaurian dinosaurs: the role of niche-partitioning in diversification
}

Article

Accepted Version

Ma, W., Brusatte, S. L., Lü, J. and Sakamoto, M. (2020) The skull evolution of oviraptorosaurian dinosaurs: the role of niche-partitioning in diversification. Journal of Evolutionary Biology, 33 (2). pp. 178-188. ISSN 1420-9101 doi: https://doi.org/10.1111/jeb.13557 Available at https://centaur.reading.ac.uk/87084/

It is advisable to refer to the publisher's version if you intend to cite from the work. See Guidance on citing.

To link to this article DOI: http://dx.doi.org/10.1111/jeb.13557

Publisher: Wiley

All outputs in CentAUR are protected by Intellectual Property Rights law, including copyright law. Copyright and IPR is retained by the creators or other copyright holders. Terms and conditions for use of this material are defined in the End User Agreement.

www.reading.ac.uk/centaur 
Central Archive at the University of Reading

Reading's research outputs online 
Article type : Research Papers

\section{The skull evolution of oviraptorosaurian dinosaurs: the role of niche- partitioning in diversification}

Waisum Ma1 ${ }^{1}$, Stephen L. Brusatte ${ }^{1}$, Junchang Lü ${ }^{2 \dagger} \&$ Manabu Sakamoto ${ }^{3}$

${ }^{1}$ School of GeoSciences, The University of Edinburgh, Edinburgh, United Kingdom

${ }^{2}$ Institute of Geology, Chinese Academy of Sciences, Beijing 100037

${ }^{3}$ University of Reading, Reading, United Kingdom

$\dagger$ Deceased

Running title: Skull evolution of oviraptorosaurs

Correspondence:

Waisum Ma, School of GeoSciences, The King's Buildings, University of Edinburgh, Edinburgh, United Kingdom

Telephone number: +4407907995477

E-mail: w.ma.1@pgr.bham.ac.uk

\section{Acknowledgements}

WM thanks David Button for his comments that greatly improve this study and Stephan Lautenschlager for his comments on the manuscript. SLB thanks his good friend, the late JL, for

This article has been accepted for publication and undergone full peer review but has not been through the copyediting, typesetting, pagination and proofreading process, which may lead to differences between this version and the Version of Record. Please cite this article as doi: 10.1111/JEB.13557

This article is protected by copyright. All rights reserved 
many years of collaboration and camaraderie. MS thanks Chris Venditti, Andrew Meade, and George Butler for invaluable discussion. SLB's work in China on Ganzhou oviraptorids was funded by a Marie Curie Career Integration Grant (EC 630652) and the University of Edinburgh, and his lab is supported by ERC StG 'PalM' (European Research Council [ERC] under the European Union's Horizon 2020 Research and Innovation Programme; Grant number: 756226). JL was supported by the National Natural Science Foundation of China (grant Nos 41672019 and 41688103). MS was supported by the Leverhulme Trust (RPG-2017-071).

This article is protected by copyright. All rights reserved 


\section{Abstract}

Oviraptorosaurs are bird-like theropod dinosaurs that thrived in the final pre-extinction ecosystems during the latest Cretaceous, and the beaked, toothless skulls of derived species are regarded as some of the most peculiar among dinosaurs. Their aberrant morphologies are hypothesized to have been caused by rapid evolution triggered by an ecological/biological driver, but little is known about how their skull shapes and functional abilities diversified. Here, we use quantitative techniques to study oviraptorosaur skull form and mandibular function. We demonstrate that the snout is particularly variable, that mandibular and upper/lower beak form are significantly correlated with phylogeny, and that there is a strong and significant correlation between mandibular function and mandible/lower beak shape, suggesting a form-function association. The form-function relationship and phylogenetic signals, along with a moderate allometric signal in lower beak form, indicate that similar mechanisms governed beak shape in oviraptorosaurs and extant birds. The two derived oviraptorosaur clades, oviraptorids and caenagnathids, are significantly separated in morphospace and functional space, indicating that they partitioned niches. Oviraptorids coexisting in the same ecosystem are also widely spread in morphological and functional space, suggesting that they finely partitioned feeding niches, whereas caenagnathids exhibit extreme disparity in beak size. The diversity of skull form and function was likely key to the diversification and evolutionary success of oviraptorosaurs in the latest Cretaceous.

Keywords: Theropoda, Dinosauria, beak, niche-partitioning, evolution, diversification

\section{Introduction}

This article is protected by copyright. All rights reserved 
Oviraptorosaurs are a group of coelurosaurian theropod dinosaurs that first appeared in the Early Cretaceous (Ji, Currie, Norell, \& Ji, 1998; Xu, Cheng, Wang, \& Chang, 2002) and later developed a huge diversity - more than $80 \%$ of the known oviraptorosaur taxa have been discovered in Late Cretaceous rocks, most of which belong to the derived subclades Oviraptoridae and Caenagnathidae. Basal oviraptorosaurs are small-bodied forms that are currently only known from Asia, whereas the derived subclades dispersed across Asia and North America and exhibited great variation in osteological features and body sizes. Oviraptorosaurs are iconic animals known from remarkable fossils, some of which are covered in feathers or preserved brooding their nests in the same style as modern birds, and were among the final major wave of dinosaur diversifications before the end-Cretaceous asteroid impact killed off the nonavian species.

Oviraptorosaurs exhibit skull forms that deviate strongly from other non-avian theropods: their skulls are relatively robust and tall, and show different levels of tooth reduction (Brusatte, Sakamoto, Montanari, Harcourt, \& William, 2012; Foth \& Rauhut, 2013; Osmolska, Currie, \& Barsbold, 2004; Xu et al., 2002). Derived oviraptorosaurs - caenagnathids and oviraptorids possess an edentulous beak and sometimes a tall cranial crest, which is pneumatized and elaborated into a variety of shapes and sizes (Lü et al., 2017; Ma et al., 2017; Osmolska et al., 2004). The unusual skulls of oviraptorosaurs probably enabled distinctive diets compared to most theropods, although feeding habits are controversial. Direct evidence of herbivory is known in some basal oviraptorosaurs (Ji et al., 1998; Ji, Lü, Wei, \& Wang, 2012; Xu et al., 2002), and diets such as herbivory, carnivory, omnivory and durophagy have been proposed for advanced oviraptorosaurs based on their osteological features (Funston \& Currie, 2014; Funston, Currie, \& Burns, 2015; Lee et al., 2019; Osmolska et al., 2004; Zanno \& Makovicky, 2011).

Previous work has detected an exceptionally high rate of cranial evolution in derived oviraptorosaurs relative to other non-avian theropods, which was hypothesized to be caused by an ecological or biological driver (Diniz-Filho et al., 2015). However, the possible drivers of this rapid rate shift have never been investigated in detail. Previous studies have also demonstrated that the cranial form (shape) of theropods is strongly correlated with phylogeny, whereas the relationship between cranial form and function is more controversial (Brusatte et al., 2012; Foth \& Rauhut, 2013). Given the aberrant nature of oviraptorosaurian skulls (Brusatte et al., 2012;

This article is protected by copyright. All rights reserved 
Foth \& Rauhut, 2013; Osmolska et al., 2004), it is unclear whether their skull forms experienced similar evolutionary constraints (i.e. phylogeny) as in theropods generally. These questions remain because the mechanisms underpinning the evolution and diversification of oviraptorosaur skulls are still poorly known and lack quantitative assessment. Answering these questions will clarify the evolutionary history of these unusual theropods. Furthermore, as oviraptorosaurs are some of the few non-avian dinosaurs that developed a completely toothless skull as in extant birds (Wang et al., 2017), understanding their history may give important insight into whether similar patterns and processes operated in independent clades of toothless dinosaurs.

In this study, we use quantitative methods to assess patterns of skull form and mandibular functional variation in oviraptorosaurs. We compare the morphospace occupation between major clades/grades to assess whether niche-partitioning likely occurred among oviraptorosaurs. We then use a series of statistical tests to evaluate the phylogenetic signals in the form datasets, as well as the correlations between form and function. The influence of body size, which is potentially correlated with skull form variation, is also assessed. This study illuminates the evolution of some of the most aberrant dinosaur skulls and examines how feeding-related nichepartitioning might have facilitated the diversification of oviraptorosaurs during the Late Cretaceous, during the last few tens of millions of years before the dinosaur extinction, particularly in Asia where many taxa often lived contemporaneously.

\section{Materials and methods}

\section{Specimens}

We included every well-preserved, published, subadult or adult oviraptorosaur skull specimen in our analysis (see the electronic supplementary material, Table S1). Juvenile specimens were excluded, to minimize the possibility that observed morphological and functional variations are ontogenetic in nature, as at least some oviraptorosaurs exhibit high variation in mandible morphology across ontogeny (Wang, Zhang, \& Yang, 2018). Thus, species known only from perinatal specimens (e.g. Yulong mini (Lü, Currie, et al., 2013) \& Beibeilong sinensis (Pu et al., 2017)) were excluded from the analysis.

This article is protected by copyright. All rights reserved 


\section{D geometric morphometric analysis}

We conducted geometric morphometric analysis to quantify the pattern of skull shape variation among oviraptorosaurs. The skull form of oviraptorosaurs was captured by plotting homologous landmarks on the lateral profile of the skulls in two-dimensional view (Figures 1, S1 \& S2; Tables S2-5). We did not place landmarks on the cranial crest region, as their morphologies are extremely variable among oviraptorosaurs (Osmolska et al., 2004) and it has been suggested that the prominent crest of Corythoraptor jacobsi likely served sociosexual functions (rather than biomechanical functions) (Lü et al., 2017); this is also likely the case for other oviraptorosaurs with elaborate crests. Excluding the crest region prevents the plausibly more feeding-related functional signals from being masked by the extreme crest variations. To detect any discrepancy in variation patterns of different parts of the skull, we divided the skull of oviraptorosaurs into four parts for separate geometric morphometric analyses: 1) cranium, 2) mandible, 3) upper beak and 4) lower beak (Figure 1; Table S6). By having four individual datasets, correlations with phylogeny and mandibular function could also be investigated separately. For each dataset, the images were compiled in the software tpsUtil (version 1.74) and imported into tpsDig (version 3.20) for landmark digitization (Rohlf, 2017). Procrustes fit was produced to standardise the landmark data using the software MorphoJ (Klingenberg, 2011). A covariate matrix was generated and lastly subjected to principal component analysis (PCA). The output principal component (PC, hereafter) scores serve as a proxy for the variation in form of oviraptorosaur skulls, which were used for further analyses to explore the correlations between form, function and phylogeny. See the electronic supplementary material section 2 for detailed methods.

\section{Functional analysis}

We quantified the functional variation among oviraptorosaur mandibles using functional characters. We developed 13 functional characters to capture different aspects of the mandibular functions of oviraptorosaurs (Note S1). All chosen characters have been demonstrated to provide feeding-related functional implications in extant animals and/or inferred in extinct animals (Note S1). We assessed these characters on 15 well-preserved mandibular specimens (Table S6). We

This article is protected by copyright. All rights reserved 
then subjected the standardised measurements to principal coordinate analysis (PCoA), using the software PAST 3.18 (Hammer, Harper, \& Ryan, 2001) (Note S2). Additional analysis was conducted to estimate the contribution of each functional character to the first two principal coordinate (PCO hereafter) axes (Note S3).

\section{Morphological and functional niche partitioning assessment}

We conducted non-parametric multivariate analysis of variance (NPMANOVA, also known as perMANOVA) to assess the degree of overlap in both the morphological and functional morphospaces between major oviraptorosaur clades/grades (i.e. basal oviraptorosaurs, caenagnathids and oviraptorids) (Table S1). This allows us to test for possible niche-partitioning. Two analyses were conducted for each pair: PC1-2/PCO1-2 and all significant PC/PCO, which are defined as the first $\mathrm{n}$ PC/PCO explaining more than $90 \%$ of the total variance in the PCA/PCoA. We conducted the NPMANOVA tests in PAST 3.18 (Hammer et al., 2001). A significant result of the NPMANOVA test signifies that the two groups are significantly separated in morphological/functional space, which is consistent with niche partitioning. We adopt a $95 \%$ confidence level as a standard for all the statistical tests in this study. The null hypothesis is rejected if the $\mathrm{p}$-value is $<0.05$. All of the $\mathrm{p}$-values were corrected for multiple comparisons in R using the Benjamini-Hochberg procedure.

\section{Evolutionary models of skull form}

We used multiple phylogenetic comparative methods to evaluate the strength and significance of the correlations between phylogeny and different parts of the skull. For all the following analyses, we used the cladogram in Lü et al. (Lü et al., 2017) to represent phylogeny (Figure S3), which we time-calibrated (Note S4).

We used Blomberg's K statistic to evaluate the strength of the phylogenetic signal in the oviraptorosaur skull form datasets. Blomberg's K statistic is a measure of phylogenetic signal in a trait dataset (Blomberg, Garland, \& Ives, 2003). A K larger than one indicates a strong phylogenetic signal, whereas K smaller than one implies otherwise (Blomberg et al., 2003). Each

This article is protected by copyright. All rights reserved 
PC was subjected to the test individually, which allows us to identify PCs that exhibit a particularly strong/weak phylogenetic signal. A corresponding p-value was also calculated for each analysis. We performed these analyses using the 'picante' package in R (Kembel et al., 2010). Additional permutation tests were conducted to assess the correlation between overall skull form (represented by PC scores from PCA) and phylogeny (Note S5) in MorphoJ (Klingenberg, 2011), which follows the permutational procedures suggested by (Laurin, 2004).

\section{Allometry}

Skull shape of animals is often correlated with size, and thus some of the PC axes generated from the skull form datasets may be allometric in nature. This phenomenon has been observed in some extant birds, for example (Bright, Marugán-Lobón, Cobb, \& Rayfield, 2016; Tokita, Yano, James, \& Abzhanov, 2017). Thus, we are interested in knowing whether similar patterns also characterise oviraptorosaurs. We used centroid size as a measure of specimen size, which in turn acts as a proxy for body size, as utilised in a previous study on theropod skulls (Brusatte et al., 2012). However, as some of the form datasets may have strong phylogenetic signals, we employed the phylogenetic eigenvector regression (PVR) technique to extract the S-component (i.e. the model residuals, which is the phylogenetically-independent component) of these variables for further correlation analysis (Diniz-Filho, de Sant'Ana, \& Bini, 1998; Diniz Filho, Bini, Sakamoto, \& Brusatte, 2014). First, the eigenvector of the time-calibrated oviraptorosaur phylogeny was extracted. Second, the S-component of each PC was extracted and tested for autocorrelation with Moran's I test to ensure the remaining phylogenetic signal is non-significant (Diniz Filho et al., 2014). If a significant phylogenetic signal was detected in the S-component (p-value <0.05), that PC was not included in the correlation test as we want to focus on detecting the correlation between size and skull forms without the potential influence of phylogenetic history. Thus, PC1 of the cranial form dataset was discarded. The S-components were regressed against centroid size (extracted from form datasets in MorphoJ (Klingenberg, 2011)) in R using the package 'PVR' (Santos, Diniz-Filho, e Luis, Bini, \& Santos, 2018) to reveal the strength and significance of their correlations.

This article is protected by copyright. All rights reserved 


\section{Form vs. function relationship}

We performed three analyses to evaluate the correlation between mandibular function and form of different parts of the skull (Note S6; Table S6). Because of the differences in sample size between the form and function datasets, additional geometric morphometrics analyses and functional analyses were conducted to match the sample size for the correlation analysis, in order to make the two datasets maximally consistent for comparison. For example, 19 and 15 specimens are present in the lower beak form and mandibular function datasets, respectively. In this case, we conducted an extra 15-taxon geometric morphometric analysis for lower beak form. Following the same principle, five additional tests were conducted: an 8-taxon PCA of cranial form, a 9-taxon PCA of upper beak form, a 15-taxon PCA of lower beak form, an 8-taxon PCoA of mandibular function and a 9-taxon PCoA of mandibular function.

Non-phylogenetic methods were used to evaluate the overall relationship between form and function, which include two-block partial least squares (2B-PLS) analysis and multivariate multiple regression (MMR) analysis (Sakamoto, 2010) (Note S6). We also ultilised a phylogenetic method, PVR, to evaluate the form and function relationship. The S-components of the significant PC/PCO of each form dataset were extracted to remove any significant phylogenetic signal from influencing the results. The first two PCs and PCOs for each dataset were retained for correlation analyses between different form and function combinations (e.g. PC1 vs PCO1, PC1 vs PCO2 etc.; except the cranial form dataset). PC1 of the cranial form dataset was not included in the analysis as a significant phylogenetic signal remains in the Scomponent. See the electronic supplementary material section 6 for detailed methods.

\section{Results}

\section{Morphological variation pattern}

The analysis on the 11-taxon cranial dataset shows that PC1 mainly describes the anteroposterior length of the external naris, the depth of the premaxilla-maxilla region and the posterior extent of the maxilla (Figure S8). PC2 largely describes the relative position of the external naris, the anterior extent of the upper beak and the size of the orbit (Figure. S8). To a lesser extent, it also

This article is protected by copyright. All rights reserved 
describes the length of the lateral temporal fenestra and the antorbital fenestra. The PC1 vs PC2 morphospace plot shows that the basal oviraptorosaur Incisivosaurus is separated from oviraptorids along both PC1 and PC2 (Figure 2A). (See the electronic supplementary material section 6 for full results.)

On the 15-taxon mandibular morphospace, PC1 largely describes the length and the height of the dentary, size of the external mandibular fenestra and the height of the coronoid process region (or the overall height of the mandible) (Figure S9). PC2 largely describes the posterior extent of the dorsal ramus of the dentary, the relative position of the external mandibular fenestra, the curvature of the ventral ramus of the dentary and the relative position of the articular glenoid (Figure. S9). The PC1 vs PC2 morphospace shows that oviraptorids and non-oviraptorids are separated along PC1 without any overlapping (Figure 2C). The non-oviraptorid taxa, caenagnathids and basal oviraptorosaurs, are separated from each other and the derived clades on PC2. The morphospace occupied by oviraptorids is visually much larger than that of caenagnathids.

On the 12-taxon upper beak morphospace, basal oviraptorosaurs are far separated from oviraptorids along PC1 (Figure 2B), as in the cranial PC plot. On the 19-taxon lower beak morphospace, PC1 largely separates the specimens into different taxonomic groups oviraptorids, basal oviraptorosaurs and caenagnathids, from left to right (with exception of Gigantoraptor, which lies close to oviraptorids) (Figure 2D). The morphospace occupations of oviraptorids and caenagnathids slightly overlap, and they do not visually exhibit prominent differences in their areas.

NPMANOVA reveals that basal oviraptorosaurs exhibit significant morphospace separation compared to oviraptorids in the mandible form, upper beak form and lower beak form datasets (Table 1). However, there is no significant separation in the cranium form morphospace. When basal oviraptorosaurs are compared to caenagnathids, there are no significant differences in any of the morphospace-overlap comparisons. However, when caenagnathids are compared to oviraptorids, these groups are significantly separated in all morphospaces.

This article is protected by copyright. All rights reserved 
Table 1. Differences in morphospace occupation between major clade/grade of Oviraptorosauria shown by NPMANOVA (p values; Bonferroni-corrected p-values (upper right)) (PC1-2/all sig $\mathrm{PC})$; significant $\mathrm{p}$-values at $\mathrm{p}<0.1(0.05<\mathrm{p}<0.1)$ are underlined.

\begin{tabular}{|c|c|c|c|}
\hline Compared groups & $\begin{array}{l}\text { Form/function } \\
\text { metric }\end{array}$ & $p$-value & $\begin{array}{l}\text { Benjamini- } \\
\text { Hochberg } \\
\text { corrected p- } \\
\text { value }\end{array}$ \\
\hline \multirow{5}{*}{$\begin{array}{l}\text { Basal oviraptorosaurs vs. } \\
\text { oviraptorids }\end{array}$} & cranium form & $0.1757 / 0.1801$ & $0.1757 / 0.1801$ \\
\hline & mandible form & $0.0185 / 0.019$ & $0.02775 / 0.0285$ \\
\hline & upper beak form & $0.0139 / 0.0164$ & $0.0139 / 0.0164$ \\
\hline & lower beak form & $0.0232 / 0.0106$ & $0.0348 / 0.0159$ \\
\hline & $\begin{array}{l}\text { mandible } \\
\text { function }\end{array}$ & $0.111 / 0.0706$ & $0.1665 / 0.1059$ \\
\hline \multirow{3}{*}{$\begin{array}{l}\text { Basal oviraptorosaurs vs. } \\
\text { caenagnathids }\end{array}$} & mandible form & $0.0696 / 0.1321$ & $0.06960 / 0.1321$ \\
\hline & lower beak form & $0.6655 / 0.1967$ & $0.6655 / 0.1967$ \\
\hline & $\begin{array}{l}\text { mandible } \\
\text { function }\end{array}$ & $0.7349 / 0.1321$ & $0.7349 / 0.1321$ \\
\hline \multirow[t]{3}{*}{$\begin{array}{l}\text { Caenagnathids vs. } \\
\text { oviraptorids }\end{array}$} & mandible form & $\begin{array}{l}0.0011 / \\
0.0011\end{array}$ & $\mathbf{0 . 0 0 3 3 / 0 . 0 0 3 3}$ \\
\hline & lower beak form & $0.0007 / 0.0003$ & $0.0021 / 0.0009$ \\
\hline & $\begin{array}{l}\text { mandible } \\
\text { function }\end{array}$ & $0.0012 / 0.001$ & $0.0036 / 0.0030$ \\
\hline
\end{tabular}

\section{Functional variation pattern}

This article is protected by copyright. All rights reserved 
In the 15-taxon dataset, there is no functional morphospace overlap between oviraptorids and other oviraptorosaurs (Figure 3). Basal oviraptorosaurs and caenagnathids overlap in their functional morphospaces, mainly because of the position of Gigantoraptor - which is closer to the oviraptorid cluster than basal oviraptorosaurs along PCO1. Basal oviraptorosaurs and oviraptorids are considerably spread out along PCO2, whereas caenagnathids are more restricted. Overall, oviraptorids appear to occupy a larger functional morphospace than caenagnathids. (See electronic supplementary material section 7 for complete results.)

NPMANOVA detected no significant difference in functional morphospace occupation between basal oviraptorosaurs and caenagnathids/oviraptorids (Table 1). However, caenagnathids and oviraptorids show significant morphospace separation, as in the mandibular and lower beak form data sets.

\section{Evolution model of skull forms}

Blomberg's K test shows that there is no significant phylogenetic signal in any of the significant PCs of the cranium matrix (Table $2 \&$ S14). However, we find a significant and strong phylogenetic signal in PC1 but not in any other PCs of the mandible and upper beak datasets. In contrast, PC1 of the lower beak form dataset shows a weak but significant phylogenetic signal (K, 0.565; p-value, 0.002), while no phylogenetic signal was detected in PC2.

The permutation test reveals that the overall shape of the oviraptorosaur cranium is not significantly correlated with phylogeny (Table S15). The overall shape of the oviraptorosaur mandible, upper beak and lower beak, however, are significantly correlated with phylogeny.

This article is protected by copyright. All rights reserved 
Table 2. Phylogenetic signal in the morphometric data shown by Blomberg's K test (see Table S14 for full results).

\begin{tabular}{|l|l|l|l|l|l|l|l|}
\hline Data & PC & K & PIC.var.obs & PIC.var.rnd.mean & p-value & $\begin{array}{l}\text { Benjamini- } \\
\text { Hochberg } \\
\text { corrected } \\
\text { p-value }\end{array}$ & PICar.Zscore \\
\hline $\begin{array}{l}\text { Cranium } \\
\text { Mandible }\end{array}$ & PC1 & 0.850 & 0.000357 & 0.000320 & 0.71 & 0.902 & 0.283 \\
\hline $\begin{array}{l}\text { Upper } \\
\text { beak }\end{array}$ & PC1 & $\mathbf{2 . 2 0 3}$ & 0.000329 & 0.00165 & $\mathbf{0 . 0 0 1}$ & $\mathbf{0 . 0 0 6}$ & -3.448 \\
\hline $\begin{array}{l}\text { Lower } \\
\text { beak }\end{array}$ & PC1 & $\mathbf{3 . 2 4 3}$ & 0.000611 & 0.00150 & $\mathbf{0 . 0 0 9}$ & & $\mathbf{0 . 0 2 7}$ \\
\hline
\end{tabular}

This article is protected by copyright. All rights reserved 


\begin{abstract}
Allometry
Regressions reveal no significant correlation between the S-component of PC scores and centroid sizes in any of the significant form PC (Table. S16). This implies that none of the significant PC variations are primarily allometric in nature. However, it is worth-noting that PC1 of lower beak form shows moderate correlation with specimen size $(p=0.08665$; corrected $p=0.25995)$.
\end{abstract}

\title{
Form and function relationship
}

2B-PLS analysis reveals no significant correlation between cranial form and mandibular function, but significant correlations between the mandible, upper beak and lower beak when each are compared to mandibular function (Table S17). No significant correlation is detected in MMR analysis between cranium form and mandibular function (Table S18). MMR analyses using different test statistics consistently show that mandible/lower beak form is significantly correlated with mandibular function. Although MMR analyses reveal that the upper beak has strong correlations with function, all the test statistics suggest these correlations to be nonsignificant, except Pillai’s trace.

PVR on form and function shows that cranium PC2 does not have a significant correlation with function PCO1 and PCO2 (Table 3 \& S19). No significant correlation is found between the upper beak and functional dataset, either. Both PC1 of the mandible and lower beak show a significant correlation with function PCO1. In comparison, the correlation between lower beak and function is slightly stronger and more significant than the one between mandible and function. PC1 of the lower beak also shows a significant correlation with function PCO2.

Table 3. Correlation between form and function shown by phylogenetic eigenvector regression (PVR) correlation test (see Table S19 for full results).

\begin{tabular}{|l|l|l|l|l|}
\hline Form & Correlation pairs & $\begin{array}{l}\text { Coefficient of } \\
\text { determination }\left(\mathrm{R}^{2}\right)\end{array}$ & -value & $\begin{array}{l}\text { Benjamini-Hochberg } \\
\text { corrected } \mathrm{p} \text {-value }\end{array}$ \\
\hline
\end{tabular}

This article is protected by copyright. All rights reserved 


\begin{tabular}{|l|l|l|l|l|}
\hline \multirow{2}{*}{ Cranium } & PC2c vs PCO1fc & 0.0113 & 0.802 & 0.954 \\
\cline { 2 - 5 } & PC2c vs PCO2fc & 0.000616 & 0.954 & 0.954 \\
\hline \multirow{2}{*}{ Mandible } & PC1m vs PCO1fm & 0.506 & $\mathbf{0 . 0 0 2 9 2}$ & $\mathbf{0 . 0 1 1 7}$ \\
\cline { 2 - 5 } & PC1m vs PCO2fm & 0.193 & 0.101 & 0.127 \\
\hline Lpper beak & PC1p vs PCO1fp & 0.190 & 0.240 & 0.321 \\
\cline { 2 - 5 } & PC1p vs PCO2fp & 0.0437 & 0.590 & 0.590 \\
\hline & PC1d vs PCO1fd & 0.535 & $\mathbf{0 . 0 0 1 9 5}$ & $\mathbf{0 . 0 0 7 8 0}$ \\
\cline { 2 - 5 } & PC1d vs PCO2fd & 0.273 & $\mathbf{0 . 0 4 5 6}$ & 0.0911 \\
\hline
\end{tabular}

\section{Discussion}

\section{Diversification of oviraptorosaur skull form}

The cranial form of oviraptorosaurs mainly varies in the snout region (premaxilla and maxilla). Overall, the modified snouts of oviraptorids are downturned compared to those of basal oviraptorosaurs: the dorsal margin of the jugal-quadratojugal and the dorsal margin of the premaxilla form an obtuse angle in lateral view. It seems reasonable that this difference implies different cranial mechanics. For example, a more inclined beak was found to be correlated with bite force increase in finches (van der Meij \& Bout, 2008). Thus, the downturned snout of oviraptorids may have been an adaptation for a powerful bite. Large variation in the shape, size and relative position of the external naris is also detected, which is perhaps related to the 
observed modification of snout orientation (PC1 \& 2; Figure S8) (Lü, Chen, Brusatte, Zhu, \& Shen, 2016; Lü et al., 2015). However, the implications of the high variability in naris shape are more difficult to explain, as the nasal region of vertebrates is related to a variety of biological roles (i.e. sound production, olfactory and respiratory) (Witmer, 2001). It is also possible that the variable external naris is a by-product of the development of a prominent cranial crest in some oviraptorosaurs, which was likely a socio-display structure (Lü et al., 2017). If this is the case, then the variation in the naris region may not imply any particular biomechanical variation among oviraptorosaurs.

The mandible and lower beak form datasets include specimens of basal oviraptorosaurs, caenagnathids and oviraptorids, allowing us to assess large-scale form variations between these major groups. The wide separation between caenagnathids and oviraptorids in the mandible form morphospace is not surprising, as their differences in mandibular anatomy are well-noted (Funston et al., 2015; Funston, Mendonca, Currie, \& Barsbold, 2017; Longrich, Barnes, Clark, \& Millar, 2013; Longrich, Currie, \& Dong, 2010; Ma et al., 2017; Osmolska et al., 2004). The lower beak form morphospace also displays a similar pattern, with most caenagnathids and oviraptorids situated at the opposing sides and basal oviraptorosaurs located between them on PC1. However, in both morphospaces, Gigantoraptor is located closer to oviraptorids than other caenagnathids and even basal oviraptorosaurs on PC1, despite phylogenetic studies consistently placing it within caenagnathids (Longrich et al., 2013; Lü et al., 2017; Yu et al., 2018). The functional morphospace shows a similar pattern with that of mandible form, as caenagnathids and oviraptorids are separated on PC1 and do not overlap. Similarly, Gigantoraptor is positioned close to the oviraptorid cluster. These results indicate that Gigantoraptor evolved a more oviraptorid-like mandible form that deviates from those of other caenagnathids, which perhaps relates to an allometric effect and/or a unique feeding style suitable for its gigantic body size (Ma et al., 2017).

Overall, the largest variation among oviraptorosaur skulls is in the rostral portion: PCs1 of the cranium and mandible datasets mainly describe variation in the snout region and the dentary region, respectively (Figures S8 \& S9). Large-scale geometric morphometric studies on theropods (Brusatte et al., 2012; Foth \& Rauhut, 2013) and extant birds (Marugán-Lobón \& Buscalioni, 2006) have consistently identified the snout to be highly variable compared to other 
parts of the cranium. Some studies focusing on particular extant bird families also found substantial cranial variation in the beak region (Grant \& Grant, 1996; Kulemeyer, Asbahr, Gunz, Frahnert, \& Bairlein, 2009; Sun, Si, Wang, Wang, \& Zhang, 2018). Our results demonstrate that this pattern still persists within a restricted taxonomic theropod group like oviraptorosaurs, despite the development of highly modified skull forms that deviate from those of other theropods (Brusatte et al., 2012; Foth \& Rauhut, 2013).

\section{Phylogenetic signals in oviraptorosaur skull forms}

There are several possible interpretations for why we did not find any phylogenetic signal in the shape of the cranium. Oviraptorosaur skull shape may have evolved under various different selection pressures. For instance, selection on feeding mechanics, olfaction, vision, intelligence, and sexual display (e.g., cranial crest) may affect skull shape evolution in wildly different ways, with the combined effect being a departure from Brownian motion in the evolution of skull shape. It is possible that phenotypic proxies for these individual selection pressures may show phylogenetic signals on their own. This is supported by the upper beak analysis, as this region shows strong phylogenetic signal $(K>3)$ while being part of the cranium, indicating that at least one cranial region evolved under potentially strong stabilizing selection $(K>1$ implies strong phylogenetic conservatism or weaker tendency to deviate away from the ancestral shape). Alternatively, failure to detect phylogenetic signal in the overall cranial shape dataset may be because of a lack of statistical power owing to small sample size $(\mathrm{N}=11)$. Because morphometric studies encompassing a wide range of non-avian theropods have detected a high phylogenetic signal in their cranial morphologies, our results indicate that such signals may be weaker within subclades (Brusatte et al., 2012; Foth \& Rauhut, 2013).

That mandible and upper beak forms both have significant and strong phylogenetic signals with $\mathrm{K}>1$-indicates that these cranio-mandibular regions are more phylogenetically 'conserved' than expected under Brownian motion. That is, closely related taxa are more similar in shape than expected given the branch lengths. Interestingly, the $\mathrm{K}<1$ in lower beak form indicates that a large proportion of lower beak shape variance cannot be explained by Brownian motion evolution alone - i.e., closely related taxa are more disparate in shape than expected given branch length - and may be indicative of additional processes like adaptive evolution or

This article is protected by copyright. All rights reserved 
directional evolution (Blomberg et al., 2003) as well as the possibility of noise in the data. The discrepancy in $\mathrm{K}$ between different parts of the skull indicates that the skull of oviraptorosaurs is not a single, well-integrated structure. A certain part, in this case the shape changes associated with PC1 in the lower beak (length and depth of the beak), may have been governed by an evolutionary process that is distinct from the other parts of the skull/mandible.

\section{Correlation of oviraptorosaur skull forms and mandible function}

Our findings that cranium and upper beak forms (the latter once accounting for phylogeny) show no significant relationships with mandibular function is consistent with previous studies (Brusatte et al., 2012; Foth \& Rauhut, 2013). However, on the contrary, we find significant relationships between mandible and lower beak forms and mandibular functions. The discrepancy in form-function relationships between the skull and mandible can possibly be explained by the fact that the cranium has multiple functional roles (e.g. feeding, neurosensory and social display etc.) whereas the role of the mandible is less variable (i.e. feeding). Thus, a single function is not capable of explaining the variance in skull shape but can do so for mandible shape. However, a study on herbivorous dinosaurs suggests that morphologically similar skulls could have disparate functional properties, as demonstrated by 3D biomechanical techniques like finite element analysis and bite force estimation (Lautenschlager, Brassey, Button, \& Barrett, 2016). It is possible that future in-depth 3D biomechanical studies would demonstrate a similar pattern in oviraptorosaur mandibles. If the close association between form and function is supported by future analysis, this would consolidate our finding that feeding mechanics likely played an important role in shaping the mandible and the lower beak of oviraptorosaurs.

\section{Beak evolution}

One of the most fascinating features of derived oviraptorosaur skulls is the presence of a toothless beak (Balanoff \& Norell, 2012; Ma et al., 2017; Osmolska et al., 2004) . Different levels of tooth reduction are known among non-avian dinosaurs (Zanno \& Makovicky, 2011), but only some oviraptorosaurs, some ornithomimosaurs and mature Limusaurus exhibit complete tooth loss as in extant birds (Makovicky, Kobayashi, \& Currie, 2004; Osmolska et al., 2004; Xu

This article is protected by copyright. All rights reserved 
et al., 2009). The beak shape of extant birds is usually regarded as closely associated with diet (Grant \& Grant, 1996; Grant \& Grant, 2006). However, recent studies demonstrate that a number of other factors may also play a role in influencing beak shape, such as phylogeny, size and function (i.e. mechanical advantage) (Bright et al., 2016; Navalón, Bright, Marugán-Lobón, \& Rayfield, 2018; Shao et al., 2016). Our results show that oviraptorosaur lower beak shape is in general closely related to phylogeny and function, as in mandible form. Interestingly, a moderate allometric signal is detected in lower beak form $\left(\mathrm{R}^{2}=0.162852 ; \mathrm{p}=0.08665\right.$; corrected $\left.\mathrm{p}=0.25995\right)$. Together, these findings may suggest that the mechanisms governing beak shape in birds are similar to those in oviraptorosaurs, despite the independent evolution of a toothless beak in these two clades.

\section{Niche partitioning between major clades of oviraptorosaurs}

Previous studies have noted a number of function-related anatomical dissimilarities between caenagnathids and oviraptorids (Funston et al., 2015; Longrich et al., 2013; Ma et al., 2017). In our study, these two clades are significantly separated from each other in both morphological and functional morphospace, as revealed by NPMANOVA. Eight functional characters are considered to have a significant contribution to functional PCO1 variations (Table S13). These characters include proxies for mechanical advantage, jaw robustness and occlusal mode (Note S1). The large separation between caenagnathids and oviraptorids in functional morphospace likely indicates that they had distinct feeding styles, corroborating previous suggestions based on comparative anatomy (Funston et al., 2015; Longrich et al., 2013; Longrich et al., 2010; Ma et al., 2017; Smith, 1992). Our results also provide quantitative support to the hypothesis that caenagnathids and oviraptorids coexisted through niche-partitioning in the Mongolian Nemegt Formation ecosystem (Funston et al., 2017), and probably other ecosystems as well. Toothed basal oviraptorosaurs likely shared similar jaw mechanics as caenagnathids because they have a number of anatomical similarities (Wang et al., 2018). The NPMANOVA tests reinforce this idea by demonstrating that basal oviraptorosaurs are not significantly separated from caenagnathids in the various morphospaces, but often are significantly separated from oviraptorids. Taken together, these results suggest that oviraptorids are a highly derived clade which developed unique mandible morphologies distinctive from other oviraptorosaurs.

This article is protected by copyright. All rights reserved 


\section{Niche partitioning within caenagnathids and oviraptorids}

The diverse mandibular function of oviraptorids has likely allowed some of them to partition feeding niches in the same ecosystem. The Late Cretaceous Nanxiong Formation in the Ganzhou region of Jiangxi, China, is the best example of within-clade co-occurrence of multiple oviraptorosaur species (Lü et al., 2017). Since 2010, seven new oviraptorids have been described from this formation (Lü et al., 2016; Lü et al., 2017; Lü et al., 2015; Lü, Yi, Zhong, \& Wei, 2013; Wang, Sun, Sullivan, \& Xu, 2013; Wei, Pu, Xu, Liu, \& Lu, 2013; Xu \& Han, 2010), leading researchers to propose that these species diversified during an evolutionary radiation, perhaps driven by differences in feeding style (Lü et al., 2016). Our results show that the Ganzhou taxa occupy a wide spread in both morphological and functional spaces (Figures. $2 \& 3$ ), instead of clustering together, supporting the hypothesis that their coexistence was facilitated by dietaryrelated niche-partitioning (see electronic supplementary material section 14).

Caenagnathids might have partitioned niches as well, but with a different strategy: they developed a wide range of body sizes (Yu et al., 2018). In the Nei Mongol Erlian Formation, Gigantoraptor, the largest known caenagnathid, has a mandible length and dentary width of 46.0 $\mathrm{cm}$ and $10.0 \mathrm{~cm}$, respectively (Ma et al., 2017). In contrast, Caenagnathasia, a small caenagnathid from the same ecosystem, has a dentary width of $1.56 \mathrm{~cm}$ (Yao et al., 2015). By having different jaw sizes, caenagnathids could have procured different types of food, and hence developed varying feeding strategies (Ma et al., 2017). It is likely that derived oviraptorosaurs caenagnathids and oviraptorids - developed different intra-clade niche-partitioning strategies to reduce competition among themselves. The high ecological variability of derived oviraptorosaurs - underpinned by their cranial and mandibular form and functional variationsmight have been key to their diversification in the Late Cretaceous, and their important role in the last pre-extinction dinosaur ecosystems of the northern hemisphere.

\section{References}

This article is protected by copyright. All rights reserved 
Balanoff, A. M., \& Norell, M. A. (2012). Osteology of Khaan mckennai (Oviraptorosauria: Theropoda). Bulletin of the American Museum of Natural History(372), 1-76.

Blomberg, S. P., Garland, T., \& Ives, A. R. (2003). Testing for phylogenetic signal in comparative data: behavioral traits are more labile. Evolution, 57(4), 717-745.

Bright, J. A., Marugán-Lobón, J., Cobb, S. N., \& Rayfield, E. J. (2016). The shapes of bird beaks are highly controlled by nondietary factors. Proceedings of the National Academy of Sciences, 201602683.

Brusatte, S. L., Sakamoto, M., Montanari, S., Harcourt, S., \& William, E. H. (2012). The evolution of cranial form and function in theropod dinosaurs: insights from geometric morphometrics. Journal of evolutionary biology, 25(2), 365-377.

Diniz-Filho, J., Alves, D., Villalobos, F., Sakamoto, M., Brusatte, S., \& Bini, L. (2015). Phylogenetic eigenvectors and nonstationarity in the evolution of theropod dinosaur skulls. Journal of evolutionary biology, 28(7), 1410-1416.

Diniz-Filho, J. A. F., de Sant'Ana, C. E. R., \& Bini, L. M. (1998). An eigenvector method for estimating phylogenetic inertia. Evolution, 52(5), 1247-1262.

Diniz Filho, J. A. F., Bini, L. M., Sakamoto, M., \& Brusatte, S. L. (2014). Phylogenetic eigenvector regression in paleobiology.

Foth, C., \& Rauhut, O. W. (2013). Macroevolutionary and morphofunctional patterns in theropod skulls: a morphometric approach. Acta Palaeontologica Polonica, 58(1), 1-16.

Funston, G. F., \& Currie, P. J. (2014). A previously undescribed caenagnathid mandible from the late Campanian of Alberta, and insights into the diet of Chirostenotes pergracilis (Dinosauria: Oviraptorosauria). Canadian Journal of Earth Sciences, 51(2), 156-165.

Funston, G. F., Currie, P. J., \& Burns, M. E. (2015). New elmisaurine specimens from North America and their relationship to the Mongolian Elmisaurus rarus. Acta Palaeontologica Polonica.

Funston, G. F., Mendonca, S. E., Currie, P. J., \& Barsbold, R. (2017). Oviraptorosaur anatomy, diversity and ecology in the Nemegt Basin. Palaeogeography, Palaeoclimatology, Palaeoecology.

Grant, B. R., \& Grant, P. R. (1996). High survival of Darwin's finch hybrids: effects of beak morphology and diets. Ecology, 77(2), 500-509.

This article is protected by copyright. All rights reserved 
Grant, P. R., \& Grant, B. R. (2006). Evolution of character displacement in Darwin's finches. Science, 313(5784), 224-226.

Hammer, Ø., Harper, D., \& Ryan, P. (2001). PAST: Paleontological Statistics software package for education and data analysis. Palaeontologia Electronica, 4(1), 1-9.

Ji, Q., Currie, P. J., Norell, M. A., \& Ji, S. A. (1998). Two feathered dinosaurs from northeastern China. Nature, 393(6687), 753-761.

Ji, Q., Lü, J., Wei, X., \& Wang, X. (2012). A new oviraptorosaur from the Yixian Formation of Jianchang, western Liaoning Province, China. Geological Bulletin of China, 31, 21022107.

Kembel, S. W., Cowan, P. D., Helmus, M. R., Cornwell, W. K., Morlon, H., Ackerly, D. D., . . . Webb, C. O. (2010). Picante: R tools for integrating phylogenies and ecology. Bioinformatics, 26(11), 1463-1464.

Klingenberg, C. P. (2011). MorphoJ: an integrated software package for geometric morphometrics. Molecular ecology resources, 11(2), 353-357.

Kulemeyer, C., Asbahr, K., Gunz, P., Frahnert, S., \& Bairlein, F. (2009). Functional morphology and integration of corvid skulls-a 3D geometric morphometric approach. Frontiers in Zoology, 6(1), 2.

Laurin, M. (2004). The evolution of body size, Cope's rule and the origin of amniotes. Systematic biology, 53(4), 594-622.

Lautenschlager, S., Brassey, C. A., Button, D. J., \& Barrett, P. M. (2016). Decoupled form and function in disparate herbivorous dinosaur clades. Scientific Reports, 6, 26495.

Lee, S., Lee, Y.-N., Chinsamy, A., Lü, J., Barsbold, R., \& Tsogtbaatar, K. (2019). A new baby oviraptorid dinosaur (Dinosauria: Theropoda) from the Upper Cretaceous Nemegt Formation of Mongolia. PLoS ONE, 14(2), e0210867.

Longrich, N. R., Barnes, K., Clark, S., \& Millar, L. (2013). Caenagnathidae from the Upper Campanian Aguja Formation of West Texas, and a Revision of the Caenagnathinae. Bulletin of the Peabody Museum of Natural History, 54(1), 23-49.

Longrich, N. R., Currie, P. J., \& Dong, Z. (2010). A new oviraptorid (Dinosauria: Theropoda) from the Upper Cretaceous of Bayan Mandahu, Inner Mongolia. Palaeontology, 53(5), 945-960.

This article is protected by copyright. All rights reserved 
Lü, J., Chen, R., Brusatte, S. L., Zhu, Y., \& Shen, C. (2016). A Late Cretaceous diversification of Asian oviraptorid dinosaurs: evidence from a new species preserved in an unusual posture. Scientific Reports, 6.

Lü, J., Currie, P. J., Xu, L., Zhang, X., Pu, H., \& Jia, S. (2013). Chicken-sized oviraptorid dinosaurs from central China and their ontogenetic implications. Naturwissenschaften, $100(2), 165-175$.

Lü, J., Li, G., Kundrát, M., Lee, Y.-N., Sun, Z., Kobayashi, Y., . . Liu, H. (2017). High diversity of the Ganzhou Oviraptorid Fauna increased by a new “cassowary-like” crested species. Scientific Reports, 7(1), 6393.

Lü, J., Pu, H., Kobayashi, Y., Xu, L., Chang, H., Shang, Y., . . Shen, C. (2015). A New Oviraptorid Dinosaur (Dinosauria: Oviraptorosauria) from the Late Cretaceous of Southern China and Its Paleobiogeographical Implications. Scientific Reports, 5. doi:10.1038/srep11490

Lü, J., Yi, L., Zhong, H., \& Wei, X. (2013). A new oviraptorosaur (Dinosauria: Oviraptorosauria) from the Late Cretaceous of southern China and its paleoecological implications. PLoS ONE, 8(11), e80557.

Ma, W., Wang, J., Pittman, M., Tan, Q., Tan, L., Guo, B., \& Xu, X. (2017). Functional anatomy of a giant toothless mandible from a bird-like dinosaur: Gigantoraptor and the evolution of the oviraptorosaurian jaw. Scientific Reports, 7, 16247.

Makovicky, P. J., Kobayashi, Y., \& Currie, P. J. (2004). Ornithomimosauria. The Dinosauria, 2 , 137-150.

Marugán-Lobón, J., \& Buscalioni, Á. D. (2006). Avian skull morphological evolution: exploring exo-and endocranial covariation with two-block partial least squares. Zoology, 109(3), 217-230.

Navalón, G., Bright, J. A., Marugán-Lobón, J., \& Rayfield, E. J. (2018). The evolutionary relationship among beak shape, mechanical advantage, and feeding ecology in modern birds. Evolution.

Osmolska, H., Currie, P. J., \& Barsbold, R. (2004). Oviraptorosauria. In D. B. Weishampel, P. Dodson, \& H. Osmolska (Eds.), The Dinosauria (Second ed., pp. 165-183): University of California Press.

This article is protected by copyright. All rights reserved 
Pu, H., Zelenitsky, D. K., Lü, J., Currie, P. J., Carpenter, K., Xu, L., . . Chuang, H. (2017). Perinate and eggs of a giant caenagnathid dinosaur from the Late Cretaceous of central China. Nature Communications, 8, 14952.

Rohlf, F. (2017). tpsDig, version 1.74. http://life.bio.sunysb.edu/morph/index.html.

Sakamoto, M. (2010). Jaw biomechanics and the evolution of biting performance in theropod dinosaurs. Proceedings of the Royal Society B: Biological Sciences, 277(1698), 33273333.

Santos, T., Diniz-Filho, J. A., e Luis, T. R., Bini, M., \& Santos, M. T. (2018). Package 'PVR'. Shao, S., Quan, Q., Cai, T., Song, G., Qu, Y., \& Lei, F. (2016). Evolution of body morphology and beak shape revealed by a morphometric analysis of 14 Paridae species. Frontiers in Zoology, 13(1), 30.

Smith, D. (1992). The type specimen of Oviraptor philoceratops, a theropod dinosaur from the Upper Cretaceous of Mongolia. Neues Jahrbuch für Geologie und Paläontologie Abhandlungen, 186(3), 365-388.

Sun, Y., Si, G., Wang, X., Wang, K., \& Zhang, Z. (2018). Geometric morphometric analysis of skull shape in the Accipitridae. Zoomorphology, 1-12.

Tokita, M., Yano, W., James, H. F., \& Abzhanov, A. (2017). Cranial shape evolution in adaptive radiations of birds: comparative morphometrics of Darwin's finches and Hawaiian honeycreepers. Phil. Trans. R. Soc. B, 372(1713), 20150481.

van der Meij, M. A., \& Bout, R. G. (2008). The relationship between shape of the skull and bite force in finches. Journal of Experimental Biology, 211(10), 1668-1680.

Wang, S., Stiegler, J., Wu, P., Chuong, C.-M., Hu, D., Balanoff, A., . . Xu, X. (2017). Heterochronic truncation of odontogenesis in theropod dinosaurs provides insight into the macroevolution of avian beaks. Proceedings of the National Academy of Sciences, 114(41), 10930-10935.

Wang, S., Sun, C., Sullivan, C., \& Xu, X. (2013). A new oviraptorid (Dinosauria: Theropoda) from the Upper Cretaceous of southern China. Zootaxa, 3640(2), 242-257.

Wang, S., Zhang, Q., \& Yang, R. (2018). Reevaluation of the dentary structures of caenagnathid oviraptorosaurs (Dinosauria, Theropoda). Scientific Reports, 8(1), 391.

This article is protected by copyright. All rights reserved 
Wei, X., Pu, H., Xu, L., Liu, D., \& Lu, J. (2013). A New Oviraptorid Dinosaur (Theropoda: Oviraptorosauria) from the Late Cretaceous of Jiangxi Province, Southern China. Acta Geologica Sinica-English Edition, 87(4), 899-904. doi:10.1111/1755-6724.12098

Witmer, L. M. (2001). Nostril position in dinosaurs and other vertebrates and its significance for nasal function. Science, 293(5531), 850-853.

Xu, X., Cheng, Y., Wang, X., \& Chang, C. (2002). An unusual oviraptorosaurian dinosaur from China. Nature, 419.

Xu, X., Clark, J. M., Mo, J., Choiniere, J., Forster, C. A., Erickson, G. M., . . Nesbitt, S. (2009). A Jurassic ceratosaur from China helps clarify avian digital homologies. Nature, 459(7249), 940.

Xu, X., \& Han, F.-L. (2010). A new oviraptorid dinosaur (Theropoda: Oviraptorosauria) from the Upper Cretaceous of China. Vertebrata Palasiatica, 48(1), 11-18.

Yao, X., Wang, X.-L., Corwin, S., Wang, S., Stidham, T., \& Xu, X. (2015). Caenagnathasia sp (Theropoda: Oviraptorosauria) from the Iren Dabasu Formation (Upper Cretaceous: Campanian) of Erenhot, Nei Mongol, China. Vertebrata Palasiatica, 53(4), 291-298.

Yu, Y., Wang, K., Chen, S., Sullivan, C., Wang, S., Wang, P., \& Xu, X. (2018). A new caenagnathid dinosaur from the Upper Cretaceous Wangshi Group of Shandong, China, with comments on size variation among oviraptorosaurs. Scientific Reports, 8(1), 5030.

Zanno, L. E., \& Makovicky, P. J. (2011). Herbivorous ecomorphology and specialization patterns in theropod dinosaur evolution. Proceedings of the National Academy of Sciences, 108(1).

This article is protected by copyright. All rights reserved 
A

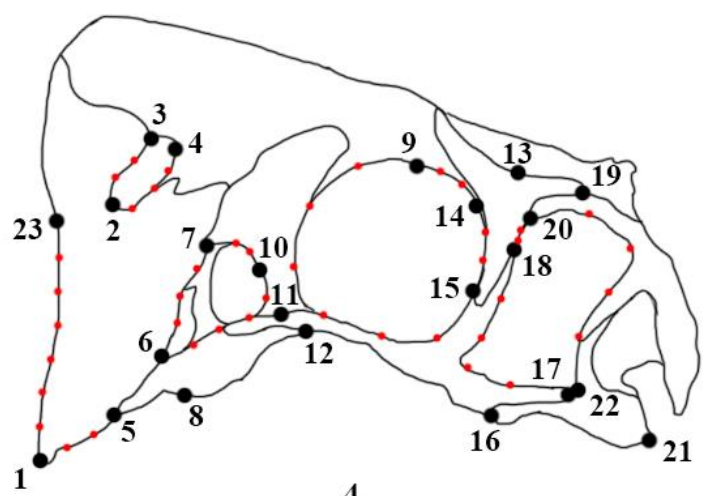

C

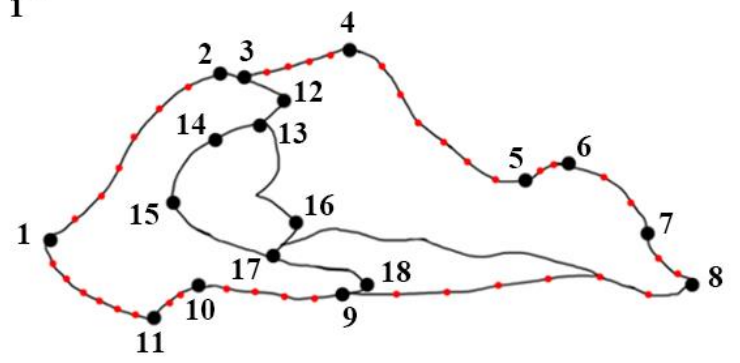

B

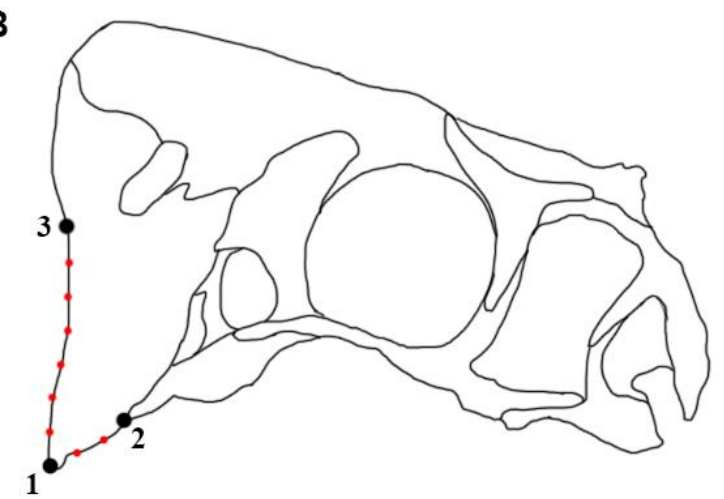

D

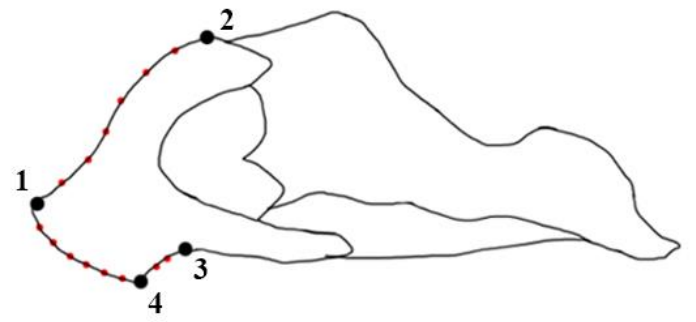

Figure 1. Homologous landmarks plotted on the (a) cranium, (b) upper beak, (c) mandible and (d) lower beak of oviraptorosaurs for geometric morphometric analysis. Black dots indicate fixed landmarks; red dots indicate semi-landmarks. See Tables S2-5 for descriptions of landmarks.

This article is protected by copyright. All rights reserved 

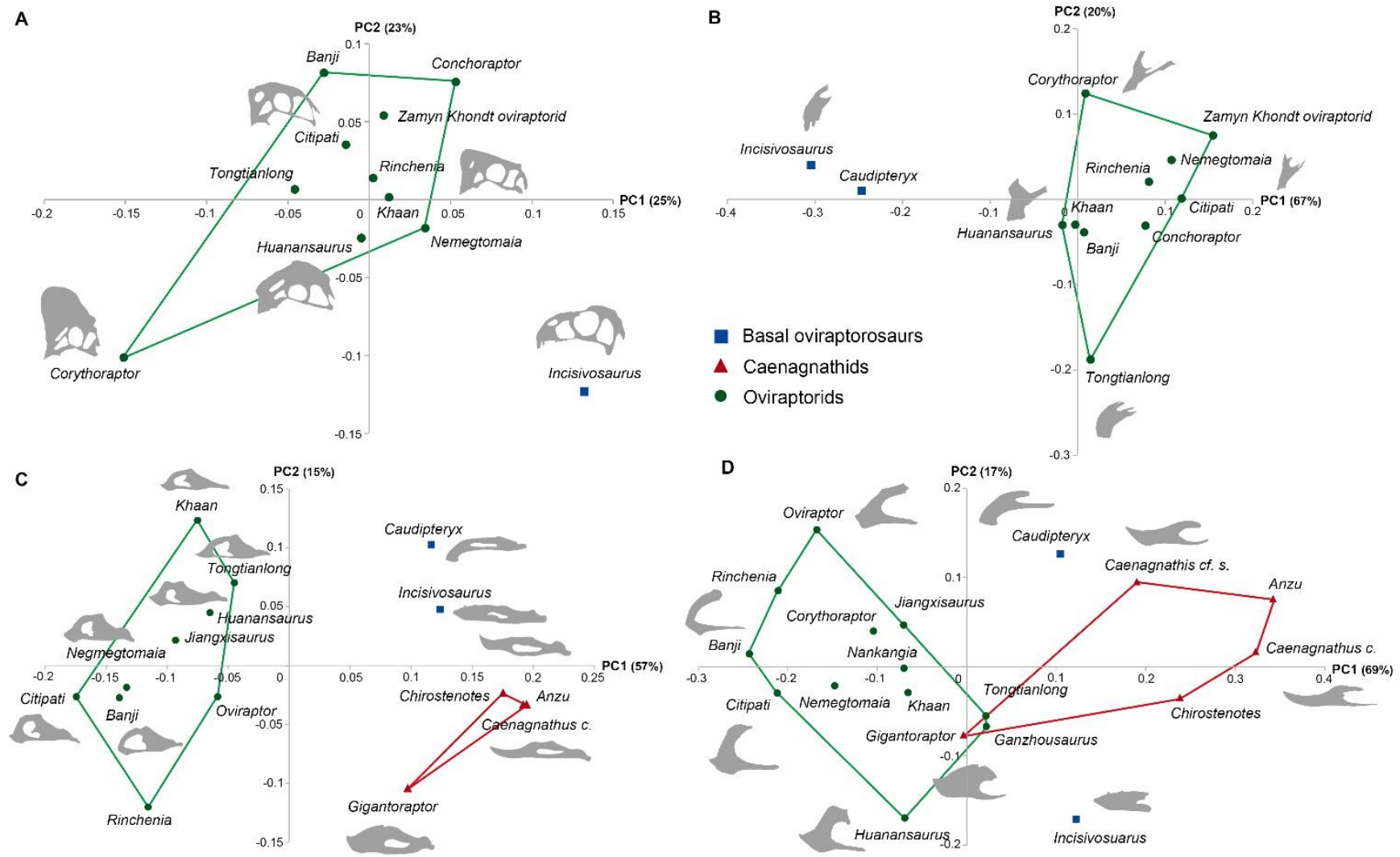

Figure 2. Two-dimensional morphospaces of oviraptorosaur skull form dataset. (A) Cranial morphospace of the 11-taxon dataset; (B) Upper beak morphospace of the 12-taxon dataset; (C) Mandibular morphospace of the 15-taxon dataset and (D) Lower beak morphospace of the 19taxon dataset. Each morphospace depicts the first PCA axis versus the second axis. See Table S1 for sources of the images used.

This article is protected by copyright. All rights reserved 


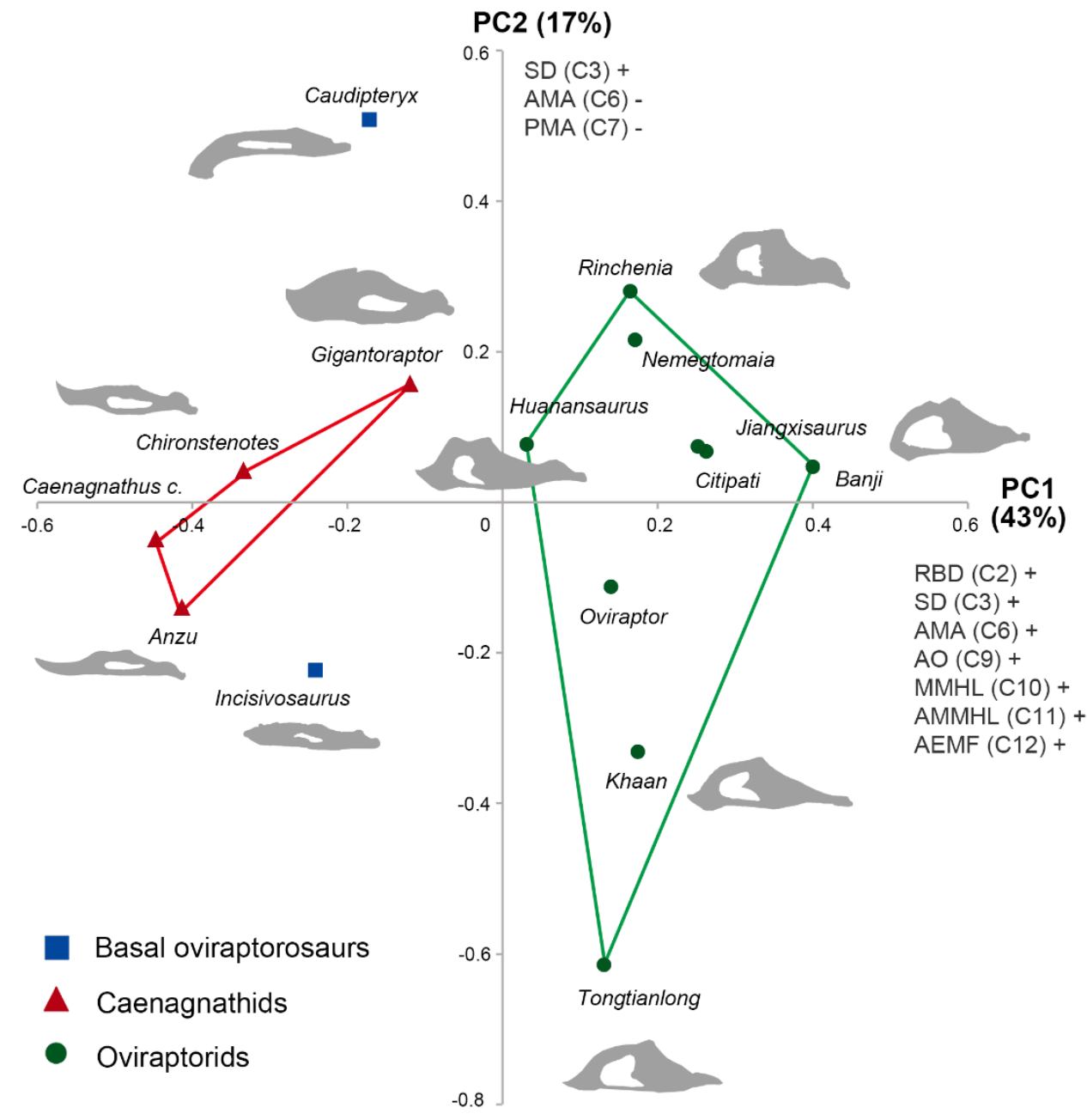

Figure 3. Two-dimensional functional morphospace of the 15-taxon mandibular function

dataset. AEMF, relative area of external mandibular fenestra; AMA, anterior mechanical advantage; AMMHL, average mandibular height; AO, articular offset; MMHL, maximum mandibular height; PMA, posterior mechanical advantage; RBD, relative beak depth; SD, symphysis deflection.

\section{Supporting information}

Table S1. List of taxon and specimens included in the geometric morphometric analysis and functional analysis.

This article is protected by copyright. All rights reserved 
Table S2. Homologous landmarks on oviraptorosaur cranium.

Table S3. Homologous landmarks on oviraptorosaur mandible.

Table S4. Homologous landmark on oviraptorosaur upper beak.

Table S5. Homologous landmark on oviraptorosaur lower beak.

Table S6. Specimens included in geometric morphometric analysis and functional analysis for each data sets.

Table S7. First occurrence of oviraptorosaur specimens.

Table S8. Morphological variation of the 11-taxon cranium form data set explained by the first 10 PCA axes.

Table S9. Morphological variation of the 15-taxon mandible form data set explained by the first 14 PCA axes.

Table S10. Morphological variation of the 12-taxon upper beak form data set explained by the first 11 PCA axes.

Table S11. Morphological variation of the 19-taxon lower beak form data set explained by the first 18 PCA axes.

Table S12. Functional variation of the 15-taxon mandibular function data set explained by the first 13 PCO axes.

Table S13. Correlations between functional characters and the first 2 PCO axes.

Table S14. Phylogenetic signal in the morphometric data shown by Blomberg's K test.

Table S15. Phylogenetic signal in the morphometric data shown by permutation test.

Table S16. Allometric signal in the morphological data shown by regression analysis between forms and specimen size (represented by centroid size).

Table S17. Correlation between form and function shown by two-block partial least squares (2BPLS) analysis.

This article is protected by copyright. All rights reserved 
Table S18. Correlation between form and function shown by multivariate multiple regression (MMR) analysis.

Table S19. Correlation between form and function shown by phylogenetic eigenvector regression (PVR) correlation test.

Table S20. Morphological variation of the 8-taxon cranium form data set explained by the first 7 PCA axes.

Table S21. Morphological variation of the 9-taxon upper beak form data set explained by the first 8 PCA axes.

Table S22. Morphological variation of the 15-taxon lower beak form data set explained by the first 14 PCA axes.

Table S23. Functional variation of the 8-taxon mandibular function data set explained by the first 8 PCO axes.

Table S24. Functional variation of the 9-taxon mandibular function data set explained by the first 9 PCO axes

Table S25. Landmarks representing different mandible sections.

Table S26. Correlation between mandible sections and overall morphology of mandible shown by two-block partial least squares (2B-PLS) analysis Table S27. Disparity analysis comparing the forms and function of caenagnathids and oviraptorids.

Table S28. Disparity analysis comparing the forms and function of Ganzhou oviraptorosaurs and non-Ganzhou oviraptorosaurs.

Table S29. Disparity analysis comparing the forms and function of Ganzhou oviraptorids and non-Ganzhou oviraptorids.

Figure S1. Homologous landmarks plotted on the (a) cranium and (b) mandible of oviraptorosaurs for geometric morphometric analysis.

Figure S2. Homologous landmarks plotted on the (a) upper beak and (b) lower beak of oviraptorosaurs for geometric morphometric analysis.

This article is protected by copyright. All rights reserved 
Figure S3. Phylogenetic trees of Oviraptorosauria used in this study.

Figure S4. Two-dimensional morphospaces with phylogenetic tree mapped for the 11-taxon cranium form data set.

Figure S5. Two-dimensional morphospaces with phylogenetic tree mapped for the 15-taxon mandible form data set.

Figure S6. Two-dimensional morphospaces with phylogenetic tree mapped for the 12-taxon upper beak form data set.

Figure S7. Two-dimensional morphospaces with phylogenetic tree mapped for the 19-taxon lower beak form data set.

Figure S8. Major shape changes in cranium based on 11-taxon data set.

Figure S9. Major shape changes in mandible based on 15-taxon data set.

Figure S10. Major shape changes in upper beak based on 12-taxon data set.

Figure S11. Major shape changes in lower beak based on 19-taxon data set.

Figure S12. Two-dimensional morphospaces with phylogenetic tree mapped for the 8-taxon cranium form data set.

Figure S13. Two-dimensional morphospaces with phylogenetic tree mapped for the 9-taxon upper beak form data set.

Figure S14. Two-dimensional morphospaces with phylogenetic tree mapped for the 15-taxon lower beak form data set.

Figure S15. Major shape changes in cranium based on 8-taxon data set.

Figure S16. Major shape changes in upper beak based on 9-taxon data set

Figure S17. Major shape changes in lower beak based on 15-taxon data set

Figure S18. Two-dimensional functional morphospaces for the 8-taxon mandibular function data set

This article is protected by copyright. All rights reserved 
Figure S19. Two-dimensional functional morphospaces for the 9-taxon mandibular function data set

Note S1. Functional characters for disparity analysis

Note S2. Disparity analysis of functional characters.

Note S3. Principal coordinate (PCO) correlation with functional characters.

Note S4. Scaling the phylogenetic tree.

Note S5. Blomberg's K statistic and permutation test.

Note S6. Non-phylogenetic and phylogenetic comparative methods.

Note S7. Morphological variation of oviraptorosaur skull forms shown by 2D geometric morphometrics.

Note S8. Correlation between overall mandibular form and its components shown by two-block partial least square (2B-PLS) analysis.

Note S9. Implications of the differences in the integration level of the mandibles of caenagnathids and oviraptorids.

Note S10. Results of disparity analysis of caenagnathids and oviraptorids.

Note S11. Discussion on disparity analysis of caenagnathids and oviraptorids.

Note S12. Results of disparity analysis of Ganzhou oviraptorids.

Note S13. Discussion on niche partitioning within Ganzhou oviraptorids.

This article is protected by copyright. All rights reserved 